\title{
Nurses' knowledge, perceived barriers, and practices regarding cancer pain management: a cross-sectional study from Palestine
}

\author{
Haneen A. Toba', Ahmad M. Samara ${ }^{1}$ and Sa'ed H. Zyoud ${ }^{2,3^{*}}$ (D)
}

\begin{abstract}
Background: Accurate knowledge and good pain evaluation and documentation practices should be present for efficient pain management. In this study, we aimed to assess the knowledge and practices of nurses relating to the management of cancer pain in Palestine, and to determine the barriers to efficient pain control in cancer patients.

Methods: A cross-sectional survey took place at 8 hospitals across Northern West Bank. A convenience sample of 220 Nurses working in governmental and private hospitals in West Bank/Palestine was studied. For that purpose, a questionnaire was developed to assess knowledge, practices, perceived barriers, and delaying processes relating to cancer pain management (CPM).

Results: In total, 220 questionnaires were completed with a response rate of 88\%. Participants' mean age was 30. 34 years. Overall, $69.5 \%$ worked in governmental hospitals, $26.8 \%$ worked in the private sector and the remainder worked in both governmental and private sectors. The correct response rate to questions that assess knowledge relating to cancer pain control was calculated and a mean knowledge score was found to be 5.1 with a standard deviation of 2.1. A relationship between the knowledge score and the sample characteristics was made and showed that males scored significantly higher $(p=0.001)$ than females with median scores of 6 [4-7] and 5 [3-6] for males and females, respectively. Inadequate pain assessment (76.8\%), insufficient knowledge of pain control (70.5\%) and strict regulation on opioid use (69.5\%) were the most frequently perceived barriers. Nurses reported that they would assess pain on every round and check all items related to pain assessment. Contacting the physician for the prescription of opioids was cited as the main delaying process by $56.4 \%$ of participants.

Conclusions: This study allowed us to recognise the knowledge deficit and the barriers to effective management. On the other hand, the analysis has shown good pain documentation practices among nurses. Those knowledge deficits demonstrate the need for more education about CPM. The improvement of coordination and communication between physicians and nurses seems to play a crucial role in CPM, as contacting physicians was cited as the most delaying process in CPM by nurses.
\end{abstract}

Keywords: Cancer pain, Nurses, Knowledge, Practices, Perceived barriers, Palestine

\footnotetext{
* Correspondence: saedzyoud@yahoo.com; saedzyoud@najah.edu

${ }^{2}$ Poison Control and Drug Information Center (PCDIC), College of Medicine and Health Sciences, An-Najah National University, Nablus 44839, Palestine ${ }^{3}$ Department of Clinical and Community Pharmacy, College of Medicine and Health Sciences, An-Najah National University, Nablus 44839, Palestine Full list of author information is available at the end of the article
}

(c) The Author(s). 2019 Open Access This article is distributed under the terms of the Creative Commons Attribution 4.0 International License (http://creativecommons.org/licenses/by/4.0/), which permits unrestricted use, distribution, and reproduction in any medium, provided you give appropriate credit to the original author(s) and the source, provide a link to the Creative Commons license, and indicate if changes were made. The Creative Commons Public Domain Dedication waiver (http://creativecommons.org/publicdomain/zero/1.0/) applies to the data made available in this article, unless otherwise stated. 


\section{Background}

Cancer patients will experience pain at some time or other. This pain can be due to the cancer's direct damage to the body or from the treatment. Overall, $92.5 \%$ of 174 cancer patients who were admitted to a pain management unit suffered from pain that was described as more than moderate despite previous treatment [1]. The low pain control quality was attributed to the under-dosage of medications, insufficient intake scheduling, and hesitancy towards using a strong opioid [1, 2].

A Jordanian study including 200 Jordanian nurses has shown that these nurses have knowledge gaps concerning pain management, which negatively impact the quality of pain control in cancer patients [3]. Nurses' knowledge about opioids' role in pain management was also reported as low by a study conducted in Italy, highlighting their irrational fear of the opioids' potential to result in addiction or respiration inhibition [4]. In Korea, another study demonstrated poor knowledge and improper practices among physicians and nurses [5].

Barriers to the adequate management of cancer pain according to an Israeli study were the inadequate assessment of pain and outcomes of treatment, insufficient knowledge among health professionals, physicians' poor attitude towards prescribing opioids, and reluctance to take opioids by patients. Interestingly, nurses' reluctance to the administration of opioids and their concerns relating to excessive regulation were not cited as common barriers to adequate pain control [6].

In Palestine, cancer is reported as the second leading cause of death (14.2\%), with cases usually being diagnosed in a late stage, leading to a greater load on patients and healthcare staff, and a poorer quality of life for patients [7], which was found to be low among Palestinian cancer patients [8]. Additionally, nurses play an essential role in cancer pain management but nursing education curriculum remain lacking in basic pain management principles [9]. To the best of our knowledge, cancer pain management (CPM), in terms of knowledge, practices and perceived barriers among Palestinian nurses, has never been targeted by research. The aim of our study was to demonstrate how each of these groups of obstacles contributes to the problem of cancer-related pain management in Palestine and the need to improve clinical practices and education, as well as related policies. In the current study, we described the knowledge and practices of nurses relating to the management of cancer pain in Palestine and highlighted some barriers that could prevent the adequate control of pain among cancer patients. By evaluating the knowledge, practices and perceived barriers relating to the management of cancer-related pain among nurses working with cancer patients, it will be easier to identify and develop educational resources and training programs for palliative care; it will also emphasise the importance of communication and consultation between healthcare professionals.

\section{Methods \\ Study design}

The study was conducted using a cross-sectional survey design.

\section{Study setting and participants}

This study took place between May and September 2017 at 8 hospitals (7 governmental and 1 private) in Northern West Bank. Nurses responsible for the care of cancer patients were eligible to participate. Institutional Review Board approval was granted by 8 participating hospitals (Al Watani/Nablus, Tubas (Turkish), Jenin (Khalil Suliman), Tulkarm (Thabit Thabit)), Salfit (Yasser Arafat), Nablus (Rafidia), Qalqiliya (Darwish Nazal) and An-Najah National University Hospital).

\section{Sample size and sampling technique}

The estimated number of nurses licensed by the Palestinian Nursing Association who worked at the surveyed hospitals and were responsible for cancer patients in their practice was around 500 [10]. Accordingly, the sample size of 218 was calculated by using Raosoft sample size calculator [11], after setting the indicator percentage at 0.50 , the margin of error at $5 \%$, and the confidence interval at $95 \%$. A convenience sample of 250 nurses in governmental and private hospitals in West Bank/Palestine was identified during the study period. In order to minimise erroneous results and to avoid dropout, we increased the target sample size to 250 nurses.

\section{Inclusion and exclusion criteria}

Inclusion criteria demands that the hospital in which the participant works admits and treats cancer patients, and that the participant is an active part of the treatment process for such patients. The exclusion criteria, on the other hand, rule out those who are not allowed to make decisions or write orders in the management of cancer patients such as students and those in training. After collecting the data, those who did not complete all items of the questionnaire were also excluded.

\section{Instruments and measures}

A questionnaire was developed based on tools that were used in previous similar studies in other countries [4-6, 12-27]. The questionnaire consisted of five main sections. The first contained the demographic data of the participants, in addition to some professional questions such as the nature and duration of their interaction with cancer patients during their work time. 
The second section included a set of 14 true or false questions to test the participants' knowledge [5] regarding the principles of managing cancer pain and differentiating it from other causes of pain, analgesic drug properties, non-pharmacological pain management, calculating opioid dose and routes of administration, the proper timing of assessment after administering the opioid, safety profile of opioid analgesics, tolerance development to opioids and the prevalence of refractory cancer pain. Subsequently, a knowledge score was calculated by allocating one point for each correctly answered question of the 14 knowledge questions and adding these points up. Higher knowledge score means better knowledge. Permission to use the questionnaire tool for this study was obtained from Professor Yeol Kim via personal email.

In addition, statements of agreement questions were used in the third and fourth sections. The third section was regarding the perceived barriers in dealing with cancer patients. Questions about perceived barriers were separated into three groups: patient-, medical staff-, and health-care system-related barriers. The forth section included questions regarding pain assessment and documentation practices and enquired about the occasions of pain assessment in cancer patients, aspects of pain assessed, and whether nurses documented pain after every assessment practice in the patient file.

The last section investigated the perceptions regarding the most delaying process in opioid administration. Four options were listed for the participants to choose from: administration of opioid to the patient, getting to the pharmacy to obtain the opioid, contacting the physician for an opioid prescription, or the delaying process is difficult to recognize.

The questionnaire was developed initially in English, and then translated into Arabic before being offered to the participants (see Additional file 1: English and Arabic version of the instrument). Face and content validity of the final questionnaire was discussed and judged by three expert's academicians in the related field for assessing the completeness, appropriateness, meaning of terms, logical sequence of the statements, and organization and the accuracy. Some questions were modified as recommended. The developed questionnaire was initially piloted among fifteen nurses before the start of the study to evaluate clarity, and time considerations; only minor modifications were needed. Internal consistency reliability for knowledge scale was good, with Cronbach's $\alpha=0.771$.

\section{Data analysis}

Descriptive analyses were implemented to describe the characteristics of participants and their answers to questions related to knowledge, practices and the perception of barriers. The relationship between knowledge score and participants characteristics was also obtained. Statistical analyses were performed using SPSS version 21.0. Statistics that present the data include frequencies and percentages, mean \pm standard deviation (SD), or median with interquartile range as appropriate. Data were analysed using the Kruskal-Wallis and Mann-Whitney U tests at $p<0.05$. Internal consistency reliability for knowledge scale was tested via Cronbach's alpha coefficient.

\section{Results \\ Sample characteristics}

In total, 250 questionnaires were distributed and 220 were completed with a response rate of $88 \%$. They had a mean age of 30.34 years $(S D=8.1)$, with a mean experience in cancer patient treatment of 5 years. Male participants comprised $47.7 \%$ of all respondents. Palestine was the country of education for most of the participants (94.5\%), with $69.5 \%$ working in governmental hospitals, $26.8 \%$ working in the private sector and the remainder working in both governmental and private sectors. Table 1 shows the demographic data and characteristics of participants.

\section{Knowledge of cancer pain management}

As shown in Table 2, the rate of correct responses to questions that assess knowledge relating to CPM was calculated; the mean knowledge score was 5.1 with a standard deviation of 2.1. The analysis showed that knowledge deficit was the highest in the question about opioid rescue dose (Opioid rescue dose equals $25 \%$ of the basal daily requirement of opioid?) with a correct response rate of $12.3 \%$, and the question about opioid risk of addiction (Opioids as analgesics have a high risk of addiction?) with a correct response rate of $14.1 \%$. A high rate of correct responses was seen in the question about the fastest route for the onset of action of opioids (The IV route for opioid administration has the fastest onset of action?) with a correct response rate of $75.5 \%$ and the question about differentiation of certain causes of pain which require specific treatment, with a correct response rate of $72.7 \%$.

Table 1 shows the association between the knowledge score and the participants' characteristics. The only factor that showed a significant difference in knowledge score is gender $(p=0.001)$ with a median score [interquartile range] of 6.0 [4.0-7.0] and 5.0 [3.0-6.0] for males and females, respectively.

\section{Perceived barriers for cancer pain management}

Table 3 demonstrates the most important barriers to CPM. Inadequate pain assessment was the most frequent medical staff-related barrier (76.8\%). As for patient-related factors, insufficient knowledge of pain control was the most encountered barrier (70.5\%). Participants perceived strict regulation of opioids use as the most common health care system-related barrier (69.5\%). 
Table 1 Relationship between knowledge score and characteristics of participants

\begin{tabular}{|c|c|c|c|}
\hline Characteristics & Number of nurses (\%) & Knowledge score ${ }^{a}$ Median [interquartile] & $P$ value $^{\mathrm{b}}$ \\
\hline \multicolumn{4}{|l|}{ Age (year) } \\
\hline Less than 40 & $183(83.2)$ & $5.0[4.0-7.0]$ & \multirow[t]{2}{*}{$0.926^{c}$} \\
\hline 40 or more & $37(16.8)$ & $5.0[4.0-7.0]$ & \\
\hline \multicolumn{4}{|l|}{ Gender } \\
\hline Male & $105(47.7)$ & $6.0[4.0-7.0]$ & \\
\hline Female & $115(52.3)$ & $5.0[3.0-6.0]$ & $0.001^{c}$ \\
\hline \multicolumn{4}{|l|}{ Country of education } \\
\hline Palestine & $208(94.5)$ & $5.0[4.0-7.0]$ & \multirow[t]{2}{*}{$0.058^{c}$} \\
\hline Abroad & $12(5.5)$ & $6.0[5.3-7.0]$ & \\
\hline \multicolumn{4}{|l|}{ Type of work } \\
\hline Governmental & $153(69.5)$ & $5.0[4.0-7.0]$ & \multirow[t]{3}{*}{$0.633^{d}$} \\
\hline Private sector & $59(26.8)$ & $5.0[4.0-7.0]$ & \\
\hline Both & $8(3.6)$ & $6.0[4.0-6.8]$ & \\
\hline \multicolumn{4}{|l|}{ General Experience } \\
\hline Less than 10 years & $152(69.1)$ & $5.0[4.0-7.0]$ & \multirow[t]{2}{*}{$0.345^{d}$} \\
\hline 10 years or more & $68(30.9)$ & $5.0[3.0-7.0]$ & \\
\hline
\end{tabular}

${ }^{a}$ Knowledge Score was a range of $0-14$, high score reflects more knowledge about cancer pain management)

${ }^{\text {b}}$ The $p$-value is bold where it is less than the significance level cut-off of 0.05

'Statistical significance of differences calculated using the Mann-Whitney $\mathrm{U}$ test

${ }^{\mathrm{d}}$ Statistical significance of differences calculated using the Kruskal-Wallis test

\section{Pain assessment practices and documentation}

Participants rated their training adequacy in CPM as excellent (9.5\%), good (42.7\%), poor (19.1\%) and very poor (28.6\%). As shown in Table 4, more than half of the participating nurses would assess the pain on every round (57.7\%). Additionally, nurses reported checking all aspects of pain during assessment with severity being the most frequently assessed item. Furthermore, $85.9 \%$ of the nurses reported that they document pain assessment.

\section{Perceptions regarding the most delaying process in opioid administration}

Table 5 shows the perceptions regarding the most delaying process in opioid administration. Contacting the

Table 2 Rate of correct answers about knowledge of cancer pain management

\begin{tabular}{|c|c|}
\hline Question $^{a}$ & Number of nurses (\%) \\
\hline 1. "You should not trust patient's subjective reports of pain" (F) & $104(47.3)$ \\
\hline 2. "You should differentiate certain cause of pain which needs specific treatment (i.e. cord compression)" (T) & $160(72.7)$ \\
\hline 3. "Prescribing a few different types of NSAIDs will increase the analgesic efficacy and decreased adverse effect" (F) & $73(33.2)$ \\
\hline 4. "Pethidine can be prescribed for chronic cancer pain safely" (F) & $67(30.5)$ \\
\hline 5. "Opioid analgesics have a high risk of addiction" (F) & $31(14.1)$ \\
\hline 6. "The effect of immediate release oral opioid can be assessed at $1 \mathrm{~h}$ after administration" $(T)$ & $83(37.7)$ \\
\hline 7. "Opioid analgesics do not have a ceiling effect" ( $T$ ) & $44(20.0)$ \\
\hline 8. "Tolerance for opioid-induced sedation develops within a few days" $(T)$ & $87(39.5)$ \\
\hline 9. "For painful bone metastasis, radiotherapy can alleviate the pain or help to reduce the amount of analgesics" (T) & $90(40.9)$ \\
\hline 10. "Opioid-induced respiratory suppression is common" (F) & $43(19.5)$ \\
\hline 11. "Celiac plexus block is effective for treating cancer pain at upper abdomen" $(T)$ & $58(26.4)$ \\
\hline 12. "Opioid rescue dose equals $25 \%$ of the basal daily requirement of opioid" (F) & $27(12.3)$ \\
\hline 13. "The IV route for opioid administration has the fastest onset of action" (T) & $166(75.5)$ \\
\hline 14. "Refractory cancer pain rarely occurs with a percent that does not exceed $5 \%$ of cancer patients" (F) & $94(42.7)$ \\
\hline Mean score, Mean (SD) & $5.1(2.1)$ \\
\hline
\end{tabular}

${ }^{\mathrm{a}}$ Questions were adapted from Jho et al. [5] 
Table 3 Perceived barriers for cancer pain management $(N=220)$

\begin{tabular}{lc}
\hline Barriers & Number of nurses (\%) \\
\hline Barriers related to medical staff & $169(76.8)$ \\
Inadequate pain assessment & $138(62.7)$ \\
Inadequate experience on pain control & $139(63.2)$ \\
Insufficient knowledge of pain control & $146(66.4)$ \\
Insufficient communication with patient & $133(60.5)$ \\
Reluctance to prescribe opioid & $143(65.0)$ \\
Barriers related to patient & $124(56.4)$ \\
Reluctance to report pain & 140 (63.6) \\
Reluctance to take opioid & $141(64.1)$ \\
Insufficient communication with medical staff & 155 (70.5) \\
Financial constraints & $153(69.5)$ \\
Insufficient knowledge of pain control & $144(65.5)$ \\
Barriers related to the health care system & 136 (61.8) \\
Strict regulation of opioids & 69 (31.4) \\
Inadequate staffing & 131 (59.5) \\
Limited stock of different types of opioids & \\
Cancer pain management is not considered as important & \\
Medication and intervention costs &
\end{tabular}

physician for the prescription of opioids was cited as the most delaying process during CPM by $56.4 \%$ of the participants, followed by obtaining opioids from the pharmacy (15\%) and finally the administration of opioids to patients $(5 \%)$. The causes of delaying processes are difficult to recognize by $23.6 \%$ of participants.

\section{Discussions}

Our study aimed to assess CPM in terms of knowledge, practices and perceived barriers among Palestinian nurses. Therefore, a questionnaire was developed and distributed with a very good response rate (88\%), which can be attributed to many factors including the relatively short duration needed to complete the questionnaire

Table 4 Pain assessment and documentation practices $(N=220)$

\begin{tabular}{ll}
\hline Type of practice & Number of nurses (\%) \\
\hline Occasion of pain assessment & $127(57.7)$ \\
Every round & $75(34.1)$ \\
On selected occasions & $18(8.2)$ \\
On rare occasions & \\
Items checked during pain assessment & $150(68.2)$ \\
Location & $130(59.1)$ \\
Quality & $112(50.9)$ \\
Related factor & $170(77.3)$ \\
Severity & $88(40.0)$ \\
Timing & $189(85.9)$ \\
Documentation of pain assessment &
\end{tabular}

and the nature of the request to complete the survey on the spot.

Our analysis has shown that nurses in Palestine have fair knowledge regarding cancer pain control, with a mean knowledge score of 5.1 out of 14, with knowledge deficits mainly regarding opioid rescue dose calculation, opioids risk of addiction, opioid-induced respiratory suppression, ceiling effect of opioids and utilization of other modalities, such as celiac plexus block. These results were consistent with previous studies which have shown that nurses had the least correct answers for questions asking about the administration of opioids and opioid physical dependency, and have also highlighted knowledge deficits in the physiology and pharmacology of pain [13, 27-30]. Although the main areas of knowledge deficits are consistent with those of the Korean study, the knowledge scores were lower than those achieved by Korean nurses in that study (mean knowledge score among nurses $=9$ out of $14, \mathrm{SD}=2.5$ ) [5]. Male nurses scored significantly higher than female nurses.

Table 5 The most common perceptions of delays in cancer pain management $(N=220)$

\begin{tabular}{ll}
\hline Causes of delays & Number of nurses (\%) \\
\hline Administration of opioid to patient & $11(5.0)$ \\
Obtaining opioid from pharmacy & $33(15.0)$ \\
Contacting physician for prescription of opioid & $124(56.4)$ \\
The delaying process is difficult to recognize & $52(23.6)$ \\
\hline
\end{tabular}


Moreover, the study participants pointed out important barriers which prevent an adequate control of cancer-related pain, such as the inadequate pain assessment by medical staff, which may be due to inadequate knowledge, an underestimation of the patients' complaint of pain [31], or inadequate communication and listening to patients [32]. Surprisingly, this shows discordance with the self-assessment of practices in pain assessment and documentation. Close discordance was found in a previous study [6]. Inadequate knowledge of pain control was highlighted as the most commonly encountered patient-related barrier and the strict regulation of opioid use as the most commonly encountered barrier related to the health care system. As barriers to the appropriate treatment of pain can vary based on the standpoint, they are considered from the patient's, physician's, or institution's standpoint, multidisciplinary initiatives should be considered to improve pain management, which may include awareness and education programs in order to change attitudes towards pain treatment [33].

Participants tended to document pain assessment frequently, which is consistent with the previous findings where nurses were reported to have better skills for assessing pain, compared to physicians and pharmacists $[5,30]$. The perception of factors that contributed to the delay in the opioid administration process has shown that contacting the physician was the most delaying process which may reflect insufficient coordination between healthcare professionals. Other sources of delay in the process of cancer pain management might exist besides the three processes which were proposed in our question, considering the significant percentage (23.6\%) of participants who found difficulty in recognizing the delaying process which may need further investigation.

\section{Strengths and limitations}

To the best of our knowledge, this is the first study to be conducted in Palestine which is concerned with nurses' knowledge and practices, as well as the perceived barriers relating to the management of cancer pain. The strengths of this study were its relatively large sample size and multicentre design. However, this study has some limitations. Firstly, the study used a convenience sample and thus results may not represent all nurses in Palestine. Secondly, closer monitoring for nursing practices is needed in order to accurately assess the actual practices in CPM. Lastly, this study is cross-sectional, where the causal relationship with the determinants could not be ascertained.

\section{Conclusions}

In conclusion, after analysing the experiences of a sample of nurses who are currently working or previously worked in $\mathrm{CPM}$, we were able to recognise the knowledge deficit with a very low mean knowledge score and the barriers to effective management. On the other hand, the analysis has shown good pain documentation practices among nurses. Those knowledge gaps demonstrate the need for various methods of education on CPM. Educating patients and caregivers about pain management is also important, as the insufficient knowledge of pain control was the most encountered patient-related barrier according to our study. The improvement of coordination and communication between physicians and nurses seems to play a crucial role in CPM, as contacting physicians was cited as the most delaying process in CPM by nurses.

\section{Additional file}

Additional file 1: Study questionnaires. This is the final English and Arabic versions of the questionnaire that was used to obtain data that helps to assess the knowledge and practices of nurses relating to the management of cancer pain, and to determine the barriers to efficient pain control in cancer patients. (DOCX $29 \mathrm{~kb}$ )

\section{Abbreviations}

CPM: Cancer pain management; IRB: Institutional review board; SD: Standard deviation

\section{Acknowledgments}

Not applicable

Funding

None

\section{Availability of data and materials}

The datasets used and/or analyzed during the current study are available from the corresponding author on reasonable request.

\section{Authors' contributions}

HT and AS conceived and carried out the study, prepared and analyzed data, and drafted the manuscript. SZ conceptualised and designed the study; coordinated, supervised, and analysed the data; critically reviewed the manuscript and the interpretation of the results; and assisted in the final write-up of the manuscript. All authors read and approved the final manuscript.

Ethics approval and consent to participate

Ethical approval was granted by the Institutional Review Board (IRB) at An-Najah National University, and permission to interview the nurses was granted from the Palestinian Ministry of Health and director of each hospital. All participants provided verbal consent to participate in the survey and their participation and attendance was voluntary.

Consent for publication

Not applicable

\section{Competing interests}

The authors declare that they have no competing interests.

\section{Publisher's Note}

Springer Nature remains neutral with regard to jurisdictional claims in published maps and institutional affiliations.

\section{Author details}

${ }^{1}$ Department of Medicine, College of Medicine and Health Sciences, An-Najah National University, Nablus 44839, Palestine. ${ }^{2}$ Poison Control and Drug Information Center (PCDIC), College of Medicine and Health Sciences, An-Najah National University, Nablus 44839, Palestine. ${ }^{3}$ Department of Clinical and Community Pharmacy, College of Medicine and Health Sciences, An-Najah National University, Nablus 44839, Palestine. 
Received: 23 February 2018 Accepted: 17 May 2019

Published online: 23 May 2019

\section{References}

1. Schug SA, Zech D, Dorr U. Cancer pain management according to $\mathrm{WHO}$ analgesic guidelines. J Pain Symptom Manag. 1990;5(1):27-32

2. Grant M, Rivera LM, Alisangco J, Francisco L. Improving cancer pain management using a performance improvement framework. J Nurs Care Qual. 1999;13(4):60-72.

3. Omran S, Al Qadire M, Ali NA, Al Hayek MF. Knowledge and attitudes about pain management: a comparison of oncology and non-oncology Jordanian nurses. Nurs Health. 2014;2(4):73-80.

4. Bernardi M, Catania G, Lambert A, Tridello G, Luzzani M. Knowledge and attitudes about cancer pain management: a national survey of Italian oncology nurses. Eur J Oncol Nurs. 2007;11(3):272-9.

5. Jho HJ, Kim Y, Kong KA, Kim DH, Choi JY, Nam EJ, Choi JY, Koh S, Hwang $\mathrm{KO}$, Baek SK, et al. Knowledge, practices, and perceived barriers regarding cancer pain management among physicians and nurses in Korea: a nationwide multicenter survey. PLOS One. 2014;9(8):e105900.

6. Sapir R, Catane R, Strauss-Liviatan N, Cherny NI. Cancer pain: knowledge and attitudes of physicians in Israel. J Pain Symptom Manage. 1999;17(4):266-76.

7. Khleif M, Dweib A. Palliative care and nursing in Palestine, 2015. J Palliat Care Med. 2015;S4:3

8. Abu Farha NH, Khatib MT, Salameh $\mathrm{H}$, Zyoud SH. Cancer-related posttreatment pain and its impact on health-related quality of life in breast cancer patients: a cross sectional study in Palestine. Asia Pac Fam Med. 2017;16:7.

9. Grant M, Ferrell B, Hanson J, Sun V, Uman G. The enduring need for the pain resource nurse (PRN) training program. J Cancer Educ. 2011;26(4):598-603.

10. Ministry of Health, Palestinian Health Information Center. Health Annual Report, Palestine 2016. 2017. \https://www.site.moh.ps/Content/Books/ ZxRcynmiUofNat66u4CrHRgmJR6Uv7z77srjjlEAho6xnz5V3rgLTu_ Rh07xf2j2VusNilvWkjwp84yXHLdGleB97gKrHHI5iZ9oPJ25owGEN.pdf. Accessed 14 Jan 2017

11. Raosoft. Sample Size Calculator. 2004. http://www.raosoft.com/samplesize. html. Accessed 20 Apr 2016.

12. Ferrell B, McCaffery M. Knowledge and attitudes survey regarding pain. 2014. http://prc.coh.org/Knowldege\%20\%20\&\%20Attitude\%20Survey\%20714\%20(1).pdf. Accessed 2 Apr 2017.

13. Manwere A, Chipfuwa T, Mukwamba MM, Chironda G. Knowledge and attitudes of registered nurses towards pain management of adult medical patients: a case of Bindura hospital. Health Sci J. 2015;9(4):3.

14. Eftekhar Z, Mohaghegh MA, Yarandi F, Eghtesadi-Araghi P, Moosavi-Jarahi A, Gilani MM, Tabatabeefar M, Toogeh G, Tahmasebi M. Knowledge and attitudes of physicians in Iran with regard to chronic cancer pain. Asian Pac J Cancer Prev. 2007:8(3):383-6.

15. Gallagher R, Hawley P, Yeomans W. A survey of cancer pain management knowledge and attitudes of British Columbian physicians. Pain Res Manag. 2004;9(4):188-94.

16. Ger LP, Ho ST, Wang JJ. Physicians' knowledge and attitudes toward the use of analgesics for cancer pain management: a survey of two medical centers in Taiwan. J Pain Symptom Manage. 2000;20(5):335-44.

17. Von Roenn JH, Cleeland CS, Gonin R, Hatfield AK, Pandya KJ. Physician attitudes and practice in cancer pain management. A survey from the eastern cooperative oncology group. Ann Intern Med. 1993;119(2):121-6.

18. Yanjun S, Changli W, Ling W, Woo JC, Sabrina K, Chang L, Lei Z. A survey on physician knowledge and attitudes towards clinical use of morphine for cancer pain treatment in China. Support Care Cancer. 2010;18(11):1455-60.

19. Zhang Q, Yu C, Feng S, Yao W, Shi H, Zhao Y, Wang Y. Physicians' practice, attitudes toward, and knowledge of Cancer pain Management in China. Pain Med. 2015:16(11):2195-203.

20. Bernardi M, Catania G, Tridello G. Knowledge and attitudes about cancer pain management: a national survey of Italian hospice nurses. Cancer Nurs. 2007;30(2):E20-6.

21. Hollen CJ, Hollen CW, Stolte K. Hospice and hospital oncology unit nurses: a comparative survey of knowledge and attitudes about cancer pain. Oncol Nurs Forum. 2000;27(10):1593-9.

22. Howell D, Butler L, Vincent L, Watt-Watson J, Stearns N. Influencing nurses' knowledge, attitudes, and practice in cancer pain management. Cancer Nurs. 2000;23(1):55-63
23. McMillan SC, Tittle M, Hagan S, Laughlin J, Tabler RE. Knowledge and attitudes of nurses in veterans hospitals about pain management in patients with cancer. Oncol Nurs Forum. 2000;27(9):1415-23.

24. O'Brien S, Dalton JA, Konsler G, Carlson J. The knowledge and attitudes of experience oncology nurses regarding the management of cancer-related pain. Oncol Nurs Forum. 1996;23(3):515-21.

25. Rushton P, Eggett D, Sutherland CW. Knowledge and attitudes about cancer pain management: a comparison of oncology and nononcology nurses. Oncol Nurs Forum. 2003;30(5):849-55.

26. Vortherms R, Ryan P, Ward S. Knowledge of, attitudes toward, and barriers to pharmacologic management of cancer pain in a statewide random sample of nurses. Res Nurs Health. 1992;15(6):459-66.

27. Yildirim YK, Cicek F, Uyar M. Knowledge and attitudes of Turkish oncology nurses about cancer pain management. Pain Manag Nurs. 2008;9(1):17-25.

28. Cindy Czaplinski RNM, Debra Harris RNM. Pain attitudes and knowledge among RNs, pharmacists, and physicians on an inpatient oncology service. Clin J Oncol Nurs. 2007;11(5):687.

29. Alnajar MK, Darawad MW, Alshahwan SS, Samarkandi OA. Knowledge and attitudes toward Cancer pain management among nurses at oncology units. J Cancer Educ. 2017.

30. Xue Y, Schulman-Green D, Czaplinski C, Harris D, McCorkle R. Pain attitudes and knowledge among RNs, pharmacists, and physicians on an inpatient oncology service. Clin J Oncol Nurs. 2007;11(5):687-95.

31. Samara AM, Toba HA, Zyoud SH. Physicians' knowledge, perceived barriers, and practices regarding cancer pain management: a cross-sectional study from Palestine. Appl Cancer Res. 2018:38(1):15

32. Prandi C, Garrino L, Mastromarino P, Torino F, Vellone E, Peruselli C, Alvaro $R$. Barriers in the management of cancer-related pain and strategies to overcome them: findings of a qualitative research involving physicians and nurses in Italy. Ann Ist Super Sanita. 2015;51(1):71-8.

33. Zuccaro SM, Vellucci $R$, Sarzi-Puttini $P$, Cherubino $P$, Labianca R, Fornasari D. Barriers to pain management: focus on opioid therapy. Clin Drug Investig. 2012:32(Suppl 1):11-9.

Ready to submit your research? Choose BMC and benefit from:

- fast, convenient online submission

- thorough peer review by experienced researchers in your field

- rapid publication on acceptance

- support for research data, including large and complex data types

- gold Open Access which fosters wider collaboration and increased citations

- maximum visibility for your research: over $100 \mathrm{M}$ website views per year

At $\mathrm{BMC}$, research is always in progress.

Learn more biomedcentral.com/submissions 